\title{
DR-11
}

\section{1,3,5-TRIAZINANES AS FORMALDIMINE SURROGATES IN THE UGI REACTION}

\author{
P. Golubev \\ Institute of Chemistry, Saint Petersburg State University, \\ 26 Universitetsky prospect, Peterhof 198504, Russia. \\ E-mail: p.r.golubev@spbu.ru
}

Abstract. In the present study, a new synthetic strategy towards $N$-acylated glycinamides was developed by the use of 1,3,5-triazinanes as formaldimine surrogates in the Ugi reaction. The targeted products were obtained in a combinatorial, diversity-oriented fashion in good yields. Further modifications allowed us to adapt this procedure for the one-pot two-step syntheses of a local anesthetic drug lidocaine and several unsymmetrically substituted diketopiperazines.

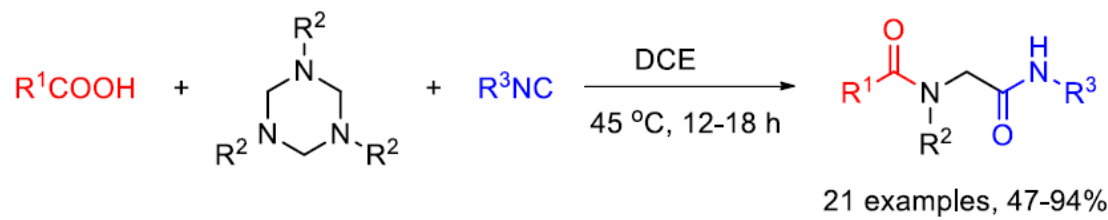

Scheme 1. Synthesis of glycinamide derivatives<smiles>CCOC(=O)CNC(=O)CN(C(=O)CNC(=O)c1ccccc1)C1CCCC1</smiles>

Figure 1. Selected examples of the synthesized compounds.

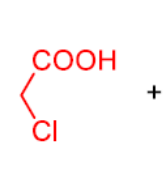<smiles>[R]N1CN([R])CN([R])C1</smiles><smiles>COc1ccccc1N</smiles>

$\frac{\text { 1. } \mathrm{CHCl}_{3}, 45^{\circ} \mathrm{C}, 12 \mathrm{~h}}{\text { 2. } \mathrm{NaH}, 40^{\circ} \mathrm{C} \text {, overnight }}$<smiles>COc1ccccc1N1CC(=O)N(Cc2ccccc2Cl)CC1=O</smiles>
$\mathrm{R}=$

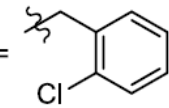

$60 \%$

Scheme 2. Synthesis of diketopiperazines.<smiles>CCN1CN(CC)CN(CC)C1</smiles><smiles>CC(=O)C=Cc1cccc(C)c1[N+]#N</smiles>

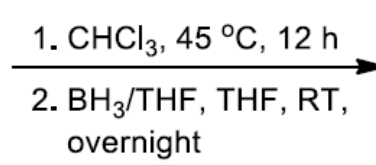
overnight<smiles>CCN(CC)CC(=O)Nc1c(C)cccc1C</smiles>

$75 \%$

Scheme 3. Synthesis of lidocaine

\section{References}

1. Golubev P. 1,3,5-Triazinanes as Formaldimine Surrogates in the Ugi Reaction / P. Golubev, N. Guranova, M. Krasavin // European Journal of Organic Chemistry. - 2020. - Vol. 2020, Iss. 29. - P. 4517-4520. 